\title{
debates
}

\section{Tradição, trote e violência}

\author{
Maria do Patrocínio Tenório Nunes Warth ${ }^{1}$ \\ Luiz Felipe Lisboa 2
}

Tradição: Transmitir

ou entregar.

Transmissão. Laço do

passado com o

presente. Costume.
Trote: Zombaria, gracejo ou indiscrição que se comete com alguém. Brincadeira que estudantes veteranos fazem com os calouros.
Violência: Constrangimento físico ou moral exercido sobre a vontade de alguém para obrigá-lo a consentir ou a submeterse à vontade de outrem. Força material ou moral empregada contra a vontade ou liberdade da pessoa. Emprego da força para superar a resistência de uma coisa ou pessoa.

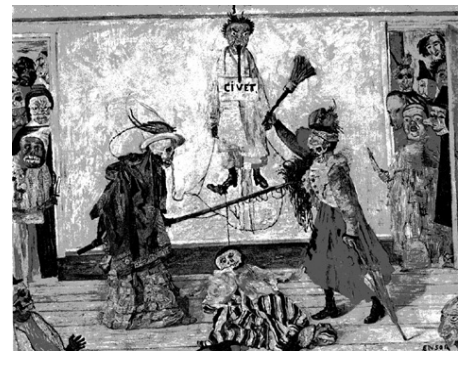

Eram os pobres novatos que os veteranos soavam à cacholeta, fraternalmente. Raul Pompéia, O Ateneu.

Vinte e dois de fevereiro de 1999.

Início do curso de graduação para 180 novos alunos da Faculdade de Medicina da USP.

Primeiro dia oficial de aulas. Como tradicionalmente ocorre há 87 anos, o curso se inicia com a aula inaugural proferida pelo Diretor da Faculdade de Medicina.

Assunto escolhido: a necessidade de praticar a medicina de maneira Tradicional: que se humanitária, mostrar as origens daquela casa aos novos membros, incorporou aos lembrar a importância do conhecimento científico, técnico e artístico da hábitos. profissão que escolheram.

Inovação: a Presidente do Centro Acadêmico Osvaldo Cruz, o Presidente da Associação Atlética Acadêmica Osvaldo Cruz, o Diretor do Departamento Científico e o Diretor do Show Medicina recepcionam os novos colegas.

\footnotetext{
${ }^{1}$ Professora do Departamento de Clínica Médica, Faculdade de Medicina, Universidade de São Paulo, USP.

${ }^{2}$ Acadêmico do $3^{\circ}$ ano de graduação, Faculdade de Medicina, USP.
} 
Durante estas apresentações, percebe-se um certo clima intimidatório por parte de alguns veteranos. Pede-se a eles que respeitem os colegas calouros $e$ veteranos. Avisa-se que os que não quiserem participar do trote podem se retirar pela porta dos fundos do Teatro da FMUSP. Aproximadamente quarenta pessoas optam por sair por aquela porta e não participar daquele tipo de comemoração.

Finda a apresentação, começa a tradicional sessão de corte de cabelos. Joga-se farinha, ovos e tintas nos novatos. $O$ clima é de festa, confraternização e intimidação. Em fila, seguem para a Atlética, antes passando pela estação de metrô, caminham aproximadamente quinhentos metros até o clube, onde os calouros são lavados. Sentados nas arquibancadas da piscina, cantam estimulados pelos veteranos........bebem.....e, finalmente, pulam na água. Chuva torrencial. Churrasco, bebidas, música... Arrastam-se pessoas pelo chão, brincadeira-da-colher etc. Tarde. Noite. Escuridão. Silêncio.

Manhã de terça-feira, 23 de fevereiro de 1999.

Sol, céu azul, calor.

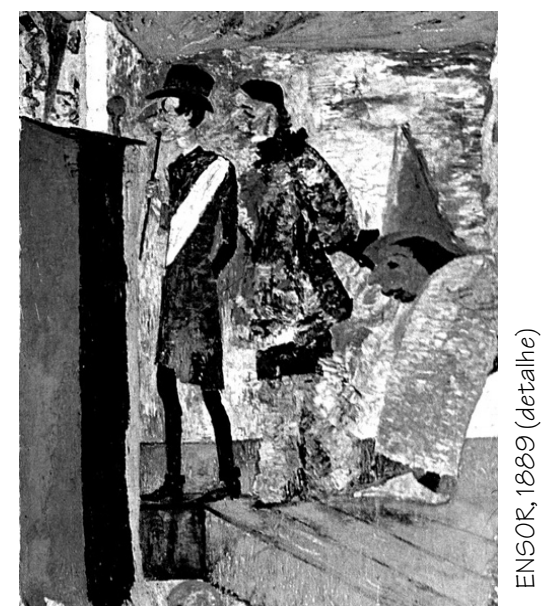
Um corpo no fundo da piscina. O corpo de um calouro da Faculdade de Medicina. Professores de diferentes disciplinas em volta da piscina. Os veteranos, os calouros... Choro. Silêncio. Tristeza. Consternação. Impotência. Medo. Aflição. Incredulidade. As horas e os dias que se seguiram foram de luto; busca pelo que teria ocorrido; enfrentamento de informações desencontradas, muitas vezes maliciosas e, por vezes, mentirosas sobre os fatos, gerando desconfiança, medo, raiva, impotência, intimidação.

Teria havido violência? Fora o aluno morto por algum ou alguns colegas emocionalmente mais descontrolados? Teria ocorrido uma sessão de tortura? O que será que levou ao fundo da piscina o jovem rapaz de 22 anos, recém-ingresso na Casa da Arnaldo?

Até o momento, não foram concluídas as investigações oficiais sobre o fato. Entretanto, das variadas versões, parece fazer sentido aquela que relaciona esta terrível perda a um lamentável acidente, que pode ter acontecido no momento do tradicional banho coletivo dos alunos na piscina, parte integrante do trote há muitos anos. O laudo de necropsia não evidenciou sinais de violência externa.

A partir deste ocorrido, iniciou-se, de maneira espontânea e ainda não organizada, uma série de discussões sobre o trote na Faculdade de Medicina da USP.

Teria o trote sido violento? Houve excessos?

As opiniões, embora muitas, podem ser resumidas em dois pólos. De um lado, aqueles que julgam ser este um dos trotes mais civilizados, dentro da USP e entre as escolas médicas. De outro, aqueles que consideram todo $e$ 
qualquer tipo de trote uma violência, com a ocorrência de excessos por parte de quem o pratica. Portanto, houve e sempre haverá, para os defensores desta idéia, violência na aplicação do trote, qualquer que seja sua forma.

Trote, na acepção que está sendo empregado, é um vocábulo usado apenas no Brasil. Em outros países recebe designações variadas. Em todos os lugares, o trote pode ser incluído entre os rituais de iniciação $e$ de passagem, de grande importância para marcar a data e a nova situação do calouro.

Relatos datados do século XII contam a ocorrência de trotes com passagens de violência física e cobrança de bens materiais por parte dos veteranos. Há uns poucos relatos de coibições oficiais, com o objetivo de proibir os excessos e conter a violência. Percebe-se, nesses relatos,

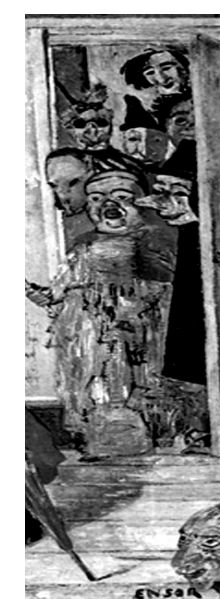
ENSOR, 1889 (detalhe)

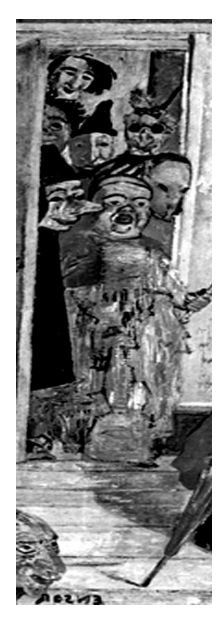

o reconhecimento de uma purgação imposta aos calouros pelos veteranos de então, com três fases bem distintas: um ritual de recepção, um período de servidão e uma emancipação. Aparentemente, este tipo de hábito se difundiu, sem grandes modificações até os dias atuais, com variantes conforme o país em que acontece.

A violência no trote pode ter culminado com a morte de um calouro já nos idos de 1831. A este fato somam-se outros tantos que comprovam a freqüencia de violência física e moral nos trotes praticados, particularmente nas escolas de Medicina, Direito e Engenharia. A busca das origens em relatos sobre trotes mostra um outro aspecto da questão, a responsabilidade e o envolvimento das instituições de ensino com o trote. Ora, o trote sempre foi o espaço e a atividade restrita aos alunos, sem qualquer participação do corpo docente. De fato, talvez o trote seja uma fórmula encontrada pelos alunos, nos primórdios das universidades, para fazer frente à relação professor/ aluno - a única oficialmente possível. Ao longo da história, apenas as tragédias suscitam algum tipo de reação nas autoridades, sob forma de proibições sumárias e punições.

A tragédia da FMUSP trouxe à tona fatos ainda não discutidos e situações complexas que precisam ser bem avaliadas.

Ao longo destes quase quatro meses, soube-se que houve, na recepção aos calouros de 1999, excessos praticados por alguns veteranos. Excessos de natureza física e psíquica. Entretanto, tais fatos surpreendem por não serem ocorrências novas. Há mais ou menos vinte ou trinta anos vinham sendo praticados. Surpreende, ainda, parte dos calouros tê-los considerado brincadeiras "normais".

A sociedade mudou. A velocidade da geração de conhecimentos, a facilidade de acesso a esses conhecimentos, o desenvolvimento tecnológico são fantásticos nos dias atuais. Apesar disto, a forma de receber os novos alunos nas faculdades, ao menos no Brasil, continua muito parecida com aquela dos tempos medievais, parece parada no tempo.

Por que indivíduos com acesso à cultura, sem grandes problemas sociais $e$ econômicos se envolvem em situações de violência e risco como já tantas vezes relatadas?

Pesquisa recente, realizada pela UNESCO em parceria com a FIOCRUZ na 
cidade do Rio de Janeiro, procurou captar e analisar como o jovem vivencia $e$ percebe a violência e a cidadania. Ouviu 1220 jovens de 15 a 19 anos, entre setembro e dezembro de 1998. Todas as formas de violência mencionadas pelos entrevistados - discussão, agressão física, venda e uso de drogas, ameaça e agressão sexual - são mais bem percebidas pelos jovens de maior poder aquisitivo. Esta percepção induz às

Cidadania: Qualidade de cidadão. Qualidade de uma pessoa que possui, em uma determinada comunidade política, o conjunto de direitos civis e políticos. seguintes conclusões: a violência parece generalizada $e$ difundida em todas as camadas sociais; existe uma diferença de percepção e tolerância em relação à violência dependendo do meio econômico, social e cultural. Aparentemente, a violência parece mais "natural" para o jovem mais pobre do que para indivíduos de classe média $e$ alta.

Segundo o coordenador da pesquisa, Júlio Jacobo Waiselfisz, a violência aparece como negação do direito do outro e emerge quando as noções de cidadania não estão consolidadas, agravando-se em condições sociais $e$ econômicas precárias. Ora, é amplamente conhecido o perfil médio do estudante de Medicina da USP. Ele faz parte das classes média e alta. Suas condições sociais e culturais não são precárias. Falta-lhe, talvez, noção de cidadania.

Sabemos que a noção de cidadania em nosso país precisa ser resgatada, ou talvez desenvolvida, já que o padrão de trote é o mesmo há cerca de vinte, trinta anos na FMUSP. Isto minimiza a explicação simplista da falta de limites e a banalização da morte pelos jovens, atualmente.

Se os alunos que adentram as faculdades de Medicina possuem, em sua maioria, um perfil que thes permite reconhecer e não tolerar a violência, como explicar o comportamento que apresentam nos rituais de recepção aos novos colegas?

Embora sem uma base científica, algumas possibilidades podem ser aventadas,

1 o ingresso nas escolas médicas é precedido por um período de grandes esforços e sacrifícios, mais ou menos duradouros. A competição, nessa época, é máxima e privilegia o desempenho individual;

2 o curso médico é física e mentalmente desgastante. Quase não há horários para os jovens se dedicarem a sua juventude;

3 o modelo de relação ainda vigente nas escolas médicas é de domínio do docente e submissão do aluno. Isto ocorre desde a situação mais "branda" de apenas injetar conhecimento sem que haja troca entre o docente e o discente, até atos como jogar o bisturi no aluno, funcionário, colega;

4 uma das características mais comuns aos médicos é o autoritarismo.

Os veteranos, principalmente os do sexto-ano, chegam em grupo para a 
recepção aos novos colegas, com uma enorme frustração contida e os calouros, reprimidos e isolados pelo preparo para o vestibular. Os primeiros querem repetir tudo (desde os tempos medievais) aquilo que fizeram com eles. Inclusive o modelo de dominação pelo poder que vêm observando durante o curso médico. Os segundos não estão amadurecidos para entender seus direitos e deveres. Ficam alienados por um bom período. Estão deslumbrados. Estão sós. Não têm um grupo em que se apoiar. Segundo o aluno Luiz Felipe Lisboa, do terceiro ano de graduação em Medicina pela FMUSP,

\begin{abstract}
"nós, estudantes de Medicina, estamos há muito com nosso limiar de violência aumentado; não consideramos violência atos estritamente desrespeitosos, invasivos, humilhantes. O que teria levado à atual situação? Talvez toda a violência externa à medicina (o mundo miserável no qual vivemos) acrescida de vidas limitadas à profissão (e a sua perspectiva). Considerando que talvez nós tenhamos um perfil psicológico extremamente diferenciado (mesmo que não seja praxe admitir ou considerar essa possibilidade), a hierarquia entre os acadêmicos dos diversos anos leva a situações de submissão à vontade ou à ordem alheia. Paralelamente, a impunidade reina (ou simplesmente os atos violentos não são trazidos à tona), pelo medo de ser segregado, isolado, tanto na vida universitária quanto no mercado de trabalho (não ser indicado por colegas etc...)".
\end{abstract}

É importante salientar que isto não implica dizer, então, que é bastante provável que alguém tenha cometido a barbaridade de assassinar friamente um colega, como vários jornalistas e outros profissionais aventaram por ocasião da tragédia da FMUSP. É leviano e violento julgar sem o conhecimento adequado da situação. A ocorrência da morte do calouro e o trote violento precisam ser adequadamente apurados. É agressivo e de repercussão desproporcional buscar um bode expiatório para a situação. Nestes quatro meses, a sociedade e a imprensa buscaram uma solução mágica e também medieval: encaminhar para a forca aquele que parecesse o mais violento dos veteranos. Se ele foi ou não o responsável pela morte do calouro, não é a questão a ser discutida. A sociedade precisa de um nome que a acalme, assim como de uma pílula para dormir ou para emagrecer. Não há interesse em discutir as causas, razões, situações. Prefere-se qualquer solução, ainda que temporária $e$ paliativa.

Recentemente o presidente norte-americano Bill Clinton solicitou um estudo sério, que busque e identifique os motivos que levam a juventude de seu país a praticar atos violentos como os que têm sido divulgados ao mundo. É necessário e urgente entender o que se passa para poder atuar adequadamente. 
E os professores $e$ as instituições? Em relação ao trote, uma parte considera que nada tem a ver com isso. Outra que o trote já deveria ter sido sumariamente proibido. Há ainda aqueles que entendem ser o trote uma atividade dos alunos e que toda e qualquer interferência externa será uma forma de intervenção nas atividades recreativas do grupo.

Há pensamentos e atitudes diferenciadas entre os docentes, mas a somatória resulta na convivência paralela de duas categorias de indivíduos dentro de um mesmo espaço: alunos e professores. Não se permite troca, o que seria altamente enriquecedor para as duas partes.

Cada grupo ou segmento social pode, sob determinadas circunstâncias, colocar em prática formas específicas de violência como garantia de sua identidade. Sujeitos envolvidos em uma situação de violência estariam se valendo desse instrumento para a construção ou garantia de manutenção de sua subjetividade marcando, assim, sua fronteira com o exterior. Seria o distanciamento da escola, na figura de seus docentes, em relação aos alunos $e$ vice-versa?

Embora com fatos pregressos a fazer estatística, não se considerou adequadamente o risco de se deixar para um grupo de pessoas o governo de uma situação cheia de possibilidade de acidentes. Para esclarecer melhor, é preciso lembrar que em qualquer lugar onde se junte bebida, extroversão, piscina, mar etc. é necessário se precaver de eventuais acidentes. E mesmo respeitosos doutores se excedem em situações como esta. Que dizer, então, de jovens que avaliam a vida como infinita e o risco de morte próximo a zero? A forma mais simplista de resolver a situação parece ser a de assinar um documento proibindo o trote nas instituições de ensino. O decreto do fim do trote não garante absolutamente nada. Talvez possamos enquadrar mais facilmente alguns exageros. Porém, nunca é demais lembrar que significará apenas a punição de alguém e não a prevenção de ocorrências desagradáveis. A proibição sumária já foi estabelecida muitas vezes e, freqüentemente, resultou em maior violência.

De mais a mais, os alunos que agora se preparam para o vestibular têm certo grau de expectativa em relação à recepção que sofrerão por época do início das aulas nas faculdades em que entrarem. Simplesmente proibir estas festas seria altamente decepcionante. É necessário lembrar, entretanto, que provavelmente ninguém (ou quase ninguém) quer ser humilhado. Toda crise traz consigo uma adição, desde que se perceba este elemento aditivo. A atitude mais sensata para reverter a situação dos trotes estudantis pode vir de uma ampla e corajosa discussão a respeito das atitudes vigentes.

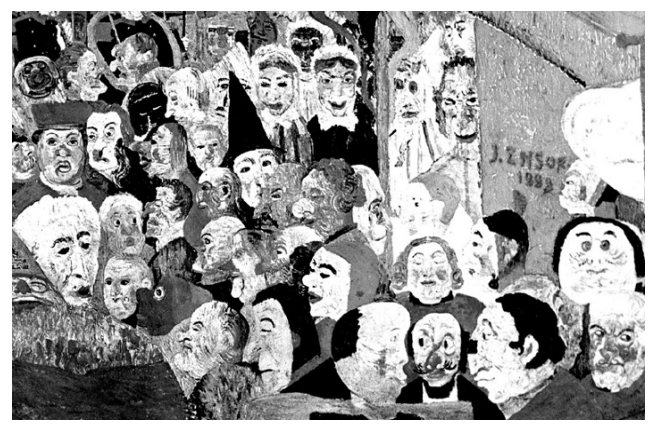

Nesse processo, é fundamental a participação eqüitativa e ativa de professores e alunos iniciando, assim, um novo paradigma de relação entre estas classes. O processo de criação das novas formas de receber calouros deve ser genuíno e pertencer àqueles com quem este aluno vai se relacionar. Romper com tradições desabonadoras é fundamental, mas um rompimento abrupto, sem preparo $e$ sem discussão e engajamento de todos os

ENSOR, Ingresso de Cristo em Bruxelas (detalhe), 1889

116 Interface - Comunic, Saúde, Educ 5 
elementos envolvidos, não terá substância suficiente para sobreviver. Certamente este ano a memória não permitirá trotes nos moldes conhecidos, mas com o tempo ela vai-se apagando e tudo volta a ser como antigamente. O processo de discussão precisa estar vivo no interior de cada escola, e se fortalecer com troca entre as escolas. Este processo precisa ser conduzido pelas lideranças estudantis e institucionais de cada local, que trabalharão com um conjunto maior, buscando uma mudança cultural, trabalhosa e longa, mas mais adequada à época em que se vive: o limiar do século XXI.

Neste processo, será fundamental, também, entender melhor os sentimentos de professores e alunos. É preciso abrir espaços de trocas entre alunos e destes com seus professores; discutir os modelos vigentes nas escolas médicas, considerando o que estes apresentam de positivo e de negativo; perceber a diversidade de pessoas que compõem um todo, buscando-se o respeito às diferenças. É imprescindível discutir a sociedade e os rumos que ela toma, o papel de cada um neste mecanismo, os valores vigentes, a participação da família na construção destes valores e sua interferência nesta fase da vida dos estudantes.

PALAVRAS-CHAVE: Violência; Universidades; trote estudantil

\section{Referências bibliográficas}

Folha de São Paulo. 3ํㅡㄹ Caderno. 25-05-1999, p.3-6.

Grande Enciclopédia Larousse Cultural

MATTOSO, G. O calvário dos carecas: história do trote estudantil. São Paulo: EMW Editores, 1985.

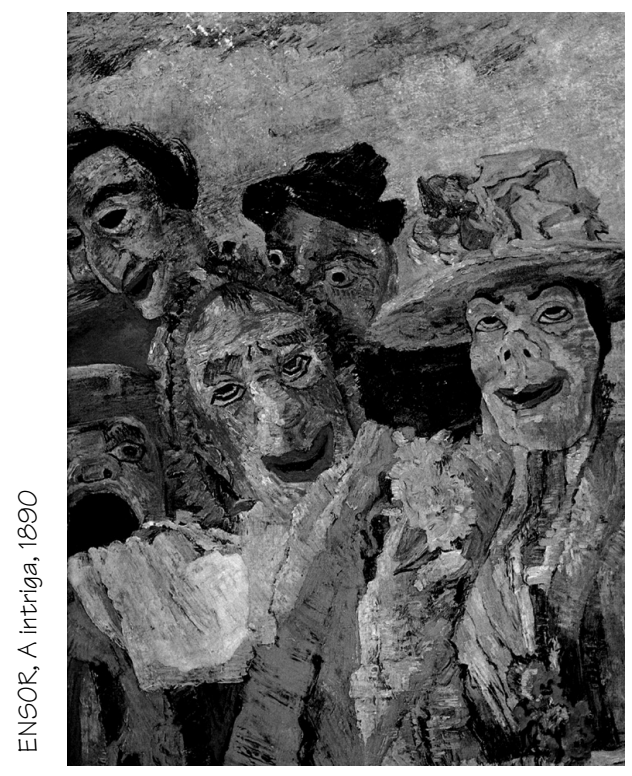

agosto, 1999 
DEBATES
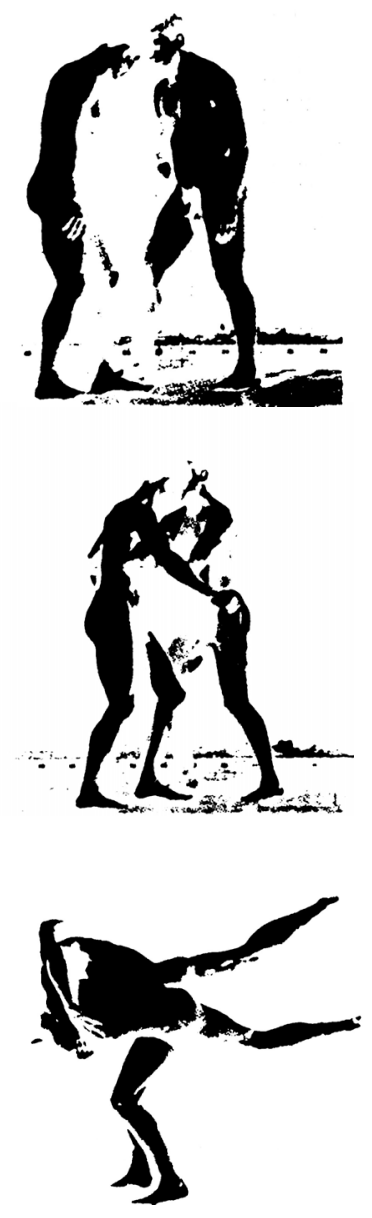

118 Interface - Comunic, Saúde, Educ 5 